\title{
O ÓXIDO NÍTRICO (NO) NO CONTROLE NEURAL DA PRESSÃO ARTERIAL: MODULAÇÃO DA TRANSMISSÃO GLUTAMATÉRGICA NO NTS
}

\author{
NITRIC OXIDE (NO) IN THE NEURAL CONTROL OF BLOOD PRESSURE: \\ MODULATION OF GLUTAMATERGIC TRANSMISSION WITHIN THE NTS
}

Ana Carolina R Dias ${ }^{1}$, Liana G da Silva² ${ }^{\text {, Eduardo Colombari }}{ }^{3}$

\begin{abstract}
${ }^{1}$ Pesquisadora. ${ }^{2}$ Aluna. Iniciação Científica. Escola Paulista de Medicina - UNIFESP. ${ }^{3}$ Docente. Departamento de Fisiologia. Escola Paulista de Medicina - UNIFESP. Departamento de Fisiologia e Patologia. Faculdade de Odontologia de Araraquara - UNESP Correspondência: Eduardo Colombari

Departamento de Fisiologia. Escola Paulista de Medicina UNIFESP

Rua Botucatu, 862 - CEP 04023-060 São Paulo- SP - Brasil

Fone: (11) 5084-9554 (ramal : 34); fax (11) 5573-7820 / E-mail: colombari@fcr.epm.br
\end{abstract}

Dias ACR, Silva LG, Colombari E. O óxido nítrico (NO) no controle neural da pressão arterial: modulação da transmissão glutamatérgica no NTS. Medicina (Ribeirão Preto) 2006; 39 (1): 51-64.

RESUMO: O efeito neuromodulatório do óxido nítrico (NO) sobre a transmissão glutamatérgica no NTS relacionado ao controle cardiovascular tem sido bastante investigado. A ativação de receptores glutamatérgicos no NTS estimula a produção e liberação de NO e outras substâncias nitrosotióis de propriedades neurotransmissoras/neuromoduladoras. A presença da enzima NOS, incluindo a proteína NOS neuronal (nNOS) e seu mRNA nos terminais das aferências vagais no NTS, além de células do gânglio nodoso sugerem que o NO possa atuar na transmissão glutamatérgica. Nossos estudos mostraram que a aplicação iontoforética do inibidor da NOS (LNAME) em neurônios do NTS que respondem à estimulação das aferências vagais diminuiu significantemente o número de potenciais de ação causados pela aplicação iontoforética de AMPA. Em contrapartida, a iontoforese do doador de NO (papaNONOate) aumentou significantemente os disparos espontâneos e o número de potenciais de ação causados pela aplicação iontoforética de AMPA, sugerindo uma facilitação pelo NO da transmissão neuronal mediada pelos receptores AMPA no NTS. As alterações da atividade nervosa simpática renal causadas pela ativação dos barorreceptores e dos receptores cardiopulmonares envolvem a estimulação dos receptores AMPA e NMDA no NTS, e estas respostas são atenuadas pela microinjeção de L-NAME no NTS de ratos anestesiados e não anestesiados. As respostas cardiovasculares obtidas com a aplicação de NO no NTS são muito similares àquelas obtidas após a estimulação das aferências vagais, e o L-glutamato é o principal neurotransmissor dessas aferências. Nesta revisão nós buscamos discutir os possíveis mecanismos neuromodulatórios do NO formado e liberado centralmente sobre a tranmissão glutamatérgica no NTS.

Descritores: AMPA. NMDA. Óxido Nítrico. Fluxo Sanguíneo Regional. Pressão Arterial. NTS. 


\section{1- INTRODUÇÃO GERAL}

O controle neural da pressão arterial tem sido motivo de estudos por várias décadas. Os avanços das técnicas de imunohistoquímica e eletrofisiologia in vivo e in vitro, aliadas ao desenvolvimento da indústria farmacêutica na síntese de compostos mais seletivos, promoveram um grande avanço na investigação da neurotransmissão dos reflexos cardiovasculares no sistema nervoso central (SNC).

Os núcleos do tracto solitário (NTS) são os sítios primários das aferências viscerais dos barorreceptores arteriais, dos receptores cardiopulmonares e dos quimiorreceptores. O NTS é essencial na modulação das funções cardiovascular, respiratória, gastrointestinal e renal ${ }^{1 / 4}$. Localizado na porção dorsomedial do bulbo, o NTS apresenta várias populações neuronais que expressam uma enorme diversidade de substâncias neurotransmissoras e neuropeptídeos ${ }^{5}$. Algumas dessas substâncias podem estar presentes somente em terminais e fibras, enquanto outras existem nos corpos celulares. A distribuição específica de cada neurotransmissor estaria associada à sua função específica na modulação ou regulação da resposta fisiológica. O glutamato, a acetilcolina e o GABA estão associados à regulação cardiovascular ${ }^{6,7,8}$. A Substância $\mathrm{P}$ está associada à modulação das respostas cardiovasculares e respiratórias ${ }^{9,10}$.

$\mathrm{Na}$ tentativa de entender a gênese e manutenção da hipertensão arterial, diversos estudos têm enfocado a participação de substâncias moduladoras da neurotransmissão dos reflexos cardiovasculares no NTS. Dentre elas o óxido nítrico (NO).

O NO é uma molécula gasosa e foi originalmente identificada como um fator endotelial relaxante do músculo liso vascular e é um importante mediador da sinalização intracelular em vários tecidos.

A descoberta de que o NO funciona como uma molécula sinalizadora no SNC mudou radicalmente o conceito de neurotransmissão ${ }^{11}$. Partindo das suas propriedades físicas, o NO não é estocado em vesículas lipídicas e liberado por exocitose, também não é metabolizado por enzimas hidrolíticas. Uma vez sintetizado difunde-se, podendo agir na própria célula em que foi produzido ou em células adjacentes (neurais ou não). Sua inativação ocorre pela reação com um substrato. Estas características sugerem que o NO tenha função neurotransmissora e neuromodulatória ${ }^{12}$.

O objetivo desta revisão é apresentar os resultados obtidos em nossos estudos sobre o papel do NO de origem central na regulação da pressão arterial e do fluxo sanguíneo regional no NTS em associação com as recentes descobertas da literatura.

\section{2- O ÓXIDO NÍTRICO DE ORIGEM CENTRAL (SÍNTESE E SINALIZAÇÃO CELULAR)}

O NO é sintetizado do seu precursor L-arginina pela enzima óxido nítrico sintase (NOS). O SNC apresenta as três isoformas da enzima NOS:

\section{1- NOS neuronal ou tipo-I (nNOS ou NOS-I)}

Originalmente identificada no tecido neural, sua ativação é regulada pelo aumento de $\mathrm{Ca}^{+2}$ intracelular. $\mathrm{O}$ influxo de $\mathrm{Ca}^{+2}$ se dá pela ativação de canais dependentes de receptores, como por exemplo, receptores NMDA (receptor ionotrópico de glutamato), ou liberação de estoques intracelulares com a chegada do potencial de ação. Quando a concentração citosólica de $\mathrm{Ca}^{+2}$ ultrapassa $400 \mathrm{mM}$, ocorre a interação deste com a calmodulina que então liga-se à nNOS ativando-a. Quando a concentração de $\mathrm{Ca}^{+2}$ diminui, ocorre a dissociação da calmodulina da enzima ${ }^{11,13,14}$. A nNOS pode estar localizada tanto pré- como pós-sinapticamente, sua distribuição é heterogênea nas diversas áreas do SNC e sua co-localização com diferentes neurotransmissores implica na participação da ativação desta isoforma na sinalização neural, neurotoxicidade, plasticidade sináptica e modulação de diversas vias neuronais ${ }^{11,15}$. Uma isoforma da $\mathrm{nNOS}$ presente na membrana da mitocôndria foi identificada, a $\operatorname{mtNOS}^{16}$. Sua função está associada com a regulação do consumo de $\mathrm{O}_{2}$ através da inibição da citocromo $c$ oxidase $^{17}$.

\section{2- NOS endotelial ou tipo-III (eNOS ou NOS-III)}

Originalmente identificada no endotélio vascular, sua ativação regula a resistência vascular. Também é $\mathrm{Ca}^{+2}-$ calmodulina dependente. No SNC está predominantemente presente no endotélio dos vasos cerebrais, em algumas populações de neurônios ${ }^{18} \mathrm{e}$ em células da glia ${ }^{19}$.

\section{3- NOS induzível ou tipo-II (iNOS ou NOS-II)}

Identificada em macrófagos e astrócitos. Está presente em menor quantidade e sua ativação é independente de $\mathrm{Ca}^{+2} \mathrm{e}$ induzida por citoquinas. No SNC é encontrada em células da glia e sua indução está associada à resposta imune inespecífica do SNC em condições patológicas ${ }^{20}$. 


\section{4- Vias alternativas de formação de NO}

Existem outras formas de produção de NO sem a ação da NOS. Reações específicas como a liberação de $\mathrm{NO}$ através da $\mathrm{H}_{2} \mathrm{O}_{2}$ e L-arginina por via não enzimática ${ }^{21}$, ou pela redução de nitritos ou outras reações de redução como em processos de isquemia ${ }^{22}$. Contudo, a principal fonte de NO é através da NOS. Cada NO gerado por uma isoforma tem função específica na célula. Logo, o controle da síntese de NO é a chave para regulação da sua atividade. A recente síntese de inibidores seletivos das isofomas da NOS tem contribuído em muito no estudo da participação do NO da modulação das diversas vias de neurotransmissão no SNC.

A enzima guanilato ciclase solúvel (GCs) é considerada o principal "receptor fisiológico" ou alvo de ação do NO de origem neuronal. O NO formado ativa a GCs resultando na produção de guanosina-3',5'monofosfato cíclico (GMPc). O NO reage com o íon ferro localizado ao centro do grupamento heme da GCs produzindo mudança conformacional, o que ativa a catalização da guanosin-5' -trifosfato (GTP) em GMPc ${ }^{23}$. O GMPc é um segundo mensageiro que ativa as proteínas quinase: PKGI (solúvel) - responsável pelo controle da quantidade de $\mathrm{Ca}^{+2}$ intracelular; PKGII (proteína de membrana) - controla o fluxo de ânions através da membrana, principalmente de íons cloreto.

Imunohistoquimicamente a distribuição da GCs e do GMPc é complementar à presença da nNOS em diversos terminais do $\mathrm{SNC}^{24,25,26}$, incluindo as aferências cardiovasculares no NTS ${ }^{1}$.

$\mathrm{O}$ NO formado se difunde rapidamente através da membrana celular e também para o interior dos vasos, onde reage com a hemoglobina $(\mathrm{Hb})$. $\mathrm{O}$ grupamento heme tem grande afinidade pelo $\mathrm{NO}$, e desta reação ocorre a formação de nitratos e metahemoglobina; o NO pode também sofrer oxidação no plasma e formar nitritos, que por sua vez reagem com $\mathrm{Hb}$ e formam nitratos. $\mathrm{O}$ grupo heme é a principal via de eliminação do $\mathrm{NO}^{27}$.

$$
\mathrm{HbO} 2+\mathrm{NO} \rightarrow \text { metHb }+\mathrm{NO}_{3}^{-}
$$

Da reação com ferro e com o grupo heme em proteínas, o NO pode formar complexos derivados de nitrosilação e ser transportado para outros tecidos ${ }^{28}$.

\section{3- O ÓXIDO NÍTRICO NO NTS E O CON- TROLE DA PRESSÃO ARTERIAL}

O termo nitrérgico foi adotado para caracterizar as estruturas do sistema nervoso que possuem funções dependentes da síntese de NO e/ou depen- dem da liberação do NO na transmissão das suas informações ${ }^{29}$.

A nNOS está presente em nervos perivasculares (nervos nitrérgicos) de diversos vasos sanguíneos e constitui um mecanismo alternativo de produção de NO para controle do fluxo sanguíneo e resistência vascular independente da eNOS ${ }^{30,31}$. No SNC, o NO derivado desta nNOS estaria associado à regulação do fluxo sanguíneo cerebral, e as maiores densidades de nNOS estão geralmente co-localizadas a neurotransmissores vasoativos ${ }^{30,32}$. As evidências de que o NO derivado da nNOS está envolvido com a modulação de funções periféricas tem crescido ultimamente. $\mathrm{O}$ NO tem sido associado ao desenvolvimento cerebral, memória, plasticidade sináptica e modulação neuroendócrina ${ }^{11}$.

Apesar das evidências acumuladas nos últimos anos que sugerem o L-glu como o principal neurotransmissor dos reflexos cardiovasculares no NTS, recentes estudos têm sugerido que o NO liberado neuronalmente, e que pode atuar tanto pré- quanto póssinapticamente, também está envolvido nesta neurotransmissão. A ativação dos receptores glutamatérgicos em diferentes sítios do sistema nervoso central induz a produção e a liberação do radical óxido nítrico (NO•) ou substâncias nitrosotióis que podem transmitir sinais para outros neurônios ${ }^{33,34}$.

Estudos de hibridização in situ demonstraram a presença da enzima NOS em neurônios e terminações no núcleo dorsal motor do vago e no NTS ${ }^{14,35,36,37}$. Houve também uma redução destas marcações para a enzima NOS nos campos de terminações no NTS após a deaferentação vagal ${ }^{36,37}$.

A microinjeção de L-glu no NTS de ratos não anestesiados causa além de hipertensão e bradicardia, vasoconstrição nos leitos renal, mesentérico e do trem posterior, sendo que, para este último é observada uma subsequente vasodilatação ${ }^{38}$. A origem e via responsáveis por esta vasodilatação não era clara, mas estudos de Davisson et al. (1996) ${ }^{39,40}$ sugeriram que a vasodilatação do trem posterior era de origem neurogênica e mediada pela liberação de fatores nitrosotióis de estoques pré-formados durante a estimulação simpática. Colombari et al. (1998) mostraram que esta vasodilatação é inibida após a administração sistêmica de inibidor da NOS (L-NAME).

Estudos de nosso laboratório buscaram discriminar as respostas hemodinâmicas pelas microinjeções dos agonistas glutamatérgicos ionotrópicos NMDA e AMPA no NTS de ratos não anestesiados. Respostas semelhantes à da microinjeção de L-glu sobre a pres- 
são arterial e frequência cardíaca foram obtidas, sendo que, a vasodilatação que foi observada com as microinjeções de L-glu foi obtida apenas nas microinjeções do agonista não-NMDA (AMPA). Esta vasodilatação persistiu mesmo após o tratamento endovenoso com antagonista de receptor muscarínico (metilatropina), sugerindo que os receptores AMPA, no NTS, podem desempenhar função diferenciada sobre o controle cardiovascular ${ }^{41}$. Distintas ou específicas respostas fisiológicas parecem ou podem ser sugeridas à estimulação de receptores NMDA e não-NMDA no NTS. Estudos eletrofisiológicos e de imunohistoquímica ${ }^{42,43,44}$ são consistentes com os resultados obtidos nos estudos com microinjeção, onde os receptores não-NMDA (AMPA) parecem desempenhar um papel específico na transmissão das aferências cardiovasculares no NTS e também em relação à interação destes com outros neurotransmissores/moduladores nestas sinapses.

A similaridade entre as respostas fisiológicas do L-glu e do NO e a distribuição de L-glu e NO nos terminais no NTS sugerem uma íntima relação entre a ação destas duas substâncias no controle cardiovascular ${ }^{2}$.

A partir da síntese de substâncias doadoras de NO e inibidoras da NOS mais específicas, evidências da participação do NO juntamente com o L-glu na transmissão dos sinais cardiovasculares no NTS vêm sendo observadas.

A ativação dos receptores glutamatérgicos em diferentes sítios do sistema nervoso central induz a produção e a liberação do radical óxido nítrico (NO•) ou substâncias nitrosotióis que podem transmitir sinais para outros neurônios ${ }^{33,34}$. Lin et al.1999 ${ }^{45}$ e $2000^{46}$ demonstraram a colocalização da NOS com as subunidades NMDA R1 e GLUR1 dos receptores NMDA e AMPA, em neurônios do NTS, sugerindo uma relação do NO ou da atividade da enzima NOS quando o receptor glutamatérgico é ativado.

A NOS imunoreativa foi localizada, além do próprio NTS, em neurônios de outros núcleos adjacentes da medula e que enviam projeções para o NTS, sugerindo a participação do NO formado por esses terminais na modulação das funções neurovegetativas tanto retrógrada, quando pré e pós-sinapticamente no $\mathrm{NTS}^{47}$. A inibição da formação do NO no NTS aumenta a atividade nervosa simpática renal em coe$\operatorname{lhos}^{48}$ e em ratos ${ }^{49}$, sugerindo a importância do NO central no controle do tônus simpático. A microinjeção de doadores de NO• no NTS induz respostas similares àquelas promovidas pela microinjeção de L-glu no mesmo sítio em animais anestesiados ${ }^{50} \mathrm{e}$ não-anestesiados $^{51}$. A transfecção de adenovirus codificado com
eNOS no NTS, causou o aumento da produção de NO o que resultou em queda da pressão arterial e frequiência cardíaca de ratos não anestesiados ${ }^{52}$.

A participação do NO nas respostas causadas pela estimulação dos receptores glutamatérgicos em neurônios do NTS, bem como o papel desta interação em situações fisiológicas que requerem a ativação destes receptores na regulação cardiovascular (estimulação dos reflexos barorreceptor e cardiopulmonar) tem sido investigado por nós nos últimos anos.

Em estudos unicelulares, observamos os efeitos do inibidor da NO sintase (L-NAME) e do doador de NO (papaNONOate) sobre o número de potenciais de ação causados pela ativação de receptores NMDA e AMPA em neurônios do NTS que respondem ao estímulo do nervo vago ${ }^{53}$. A aplicação iontoforética de L-NAME não alterou a frequência de disparos espontânea dos neurônios, mas diminuiu significantemente o número de potenciais de ação causados pela aplicação iontoforética de AMPA $^{53}$ (Figura 1).
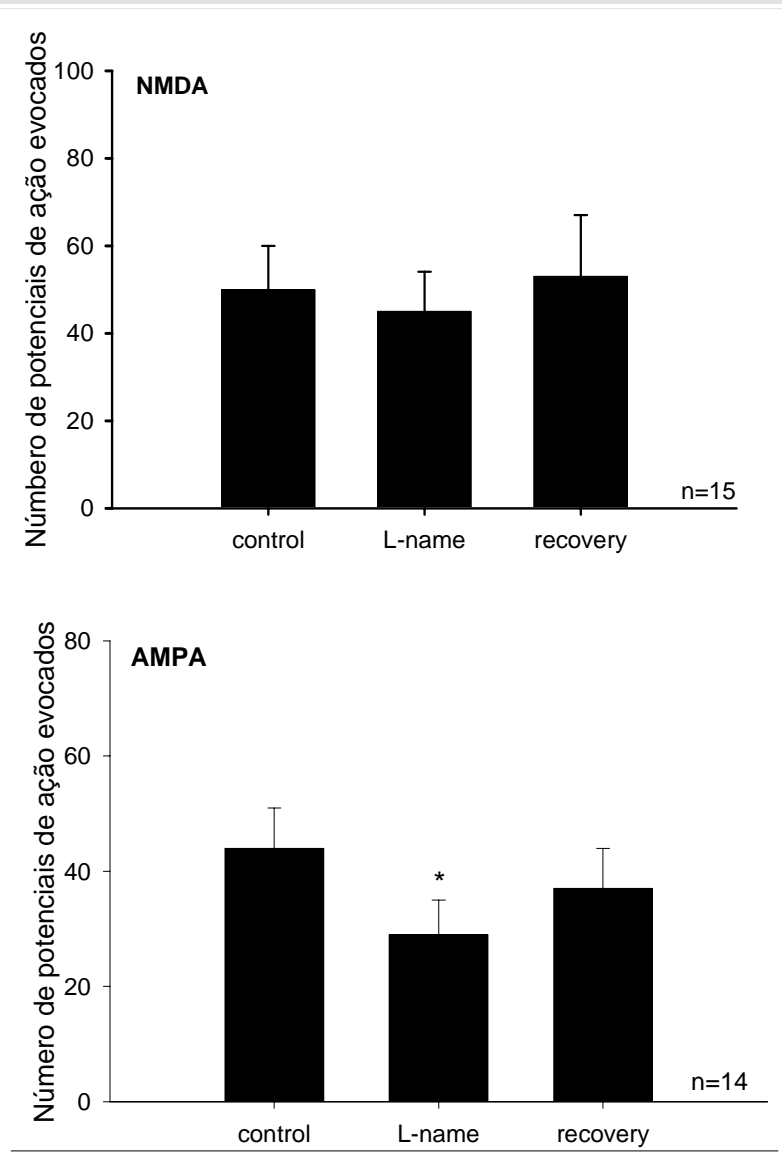

Figura 1: Alteração do número de potenciais de ação causados pela corrente iontoforética de NMDA $(10-20 n A, n=15)$ e AMPA (10-20nA, n=14) antes (control), durante a aplicação da corrente contínua de L-NAME (40 nA) e após (recovery) em neurônios do NTS que recebem aferências vagais. * ANOVA, $p<0,05$. 
A iontoforese do doador de NO (papaNONOate) aumentou significantemente o número de potenciais de ação causados pela aplicação iontoforética de AMPA, mas não alterou o número de potenciais de ação causados pela estimulação dos receptores NMDA. Os efeitos do L-NAME e do papaNONOate sobre as respostas causadas pelo NMDA foram variáveis, contudo, não significantes para a população de neurônios testada. A iontoforese dos isômeros inativos D-NAME e sulfoNONOate não causaram efeito sobre as respostas neuronais causadas pelo AMPA (Figura 2). Estes resultados sugerem uma facilitação da transmissão neuronal mediada pelos receptores AMPA no NTS pelo $\mathrm{NO}^{53}$.
Em complementação aos estudos neuronais, foram realizados experimentos de microinjeção onde observamos os efeitos fisiológicos dessa relação entre NO e a transmissão glutamatérgica no NTS, medindo o contingente eferente pós-sináptico do reflexo baroceptor arterial, a atividade nervosa simpática renal (RSNA). A inibição da NOS (L-NAME) no NTS de ratos anestesiados reduziu significantemente a hipotensão e a inibição da RSNA causadas pela microinjeção de AMPA e NMDA no NTS de ratos anestesiados ${ }^{54}$ (Figura 3). Resultado semelhante foi observado por Lo et al. (1997) ${ }^{55}$, pela inibição da NOS com L-NMMA, o que reforça a idéia de uma ação recíproca do NO neuronal e da ativação dos receptores glutamatérgicos ionotrópicos no NTS.

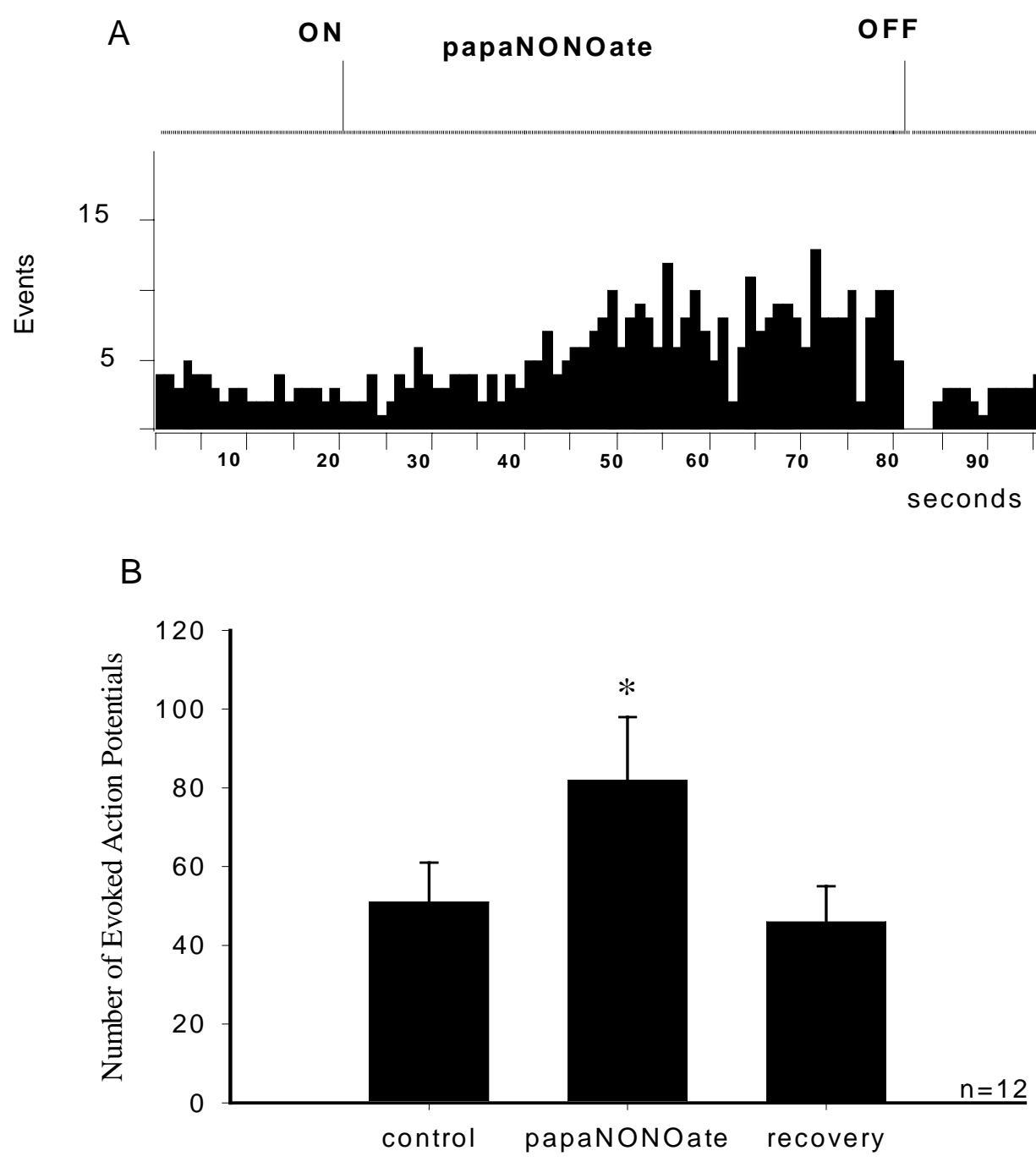

Figura 2: A) traçado representativo do efeito da aplicação iontoforética de papaNONOate sobre a frequência de disparos basais de um neurônio do NTS. A barra indica o período da ejeção da corrente de papaNONOate. B) Número de potenciais de ação evocados pela aplicação iontoforética de AMPA antes (control), durante (papaNONOate) e após (recovery) a corrente de papaNONOate $\left(n=12,{ }^{*}\right.$ ANOVA $\left.p<0.05\right)$. Dias et al. $2001^{41}$. 


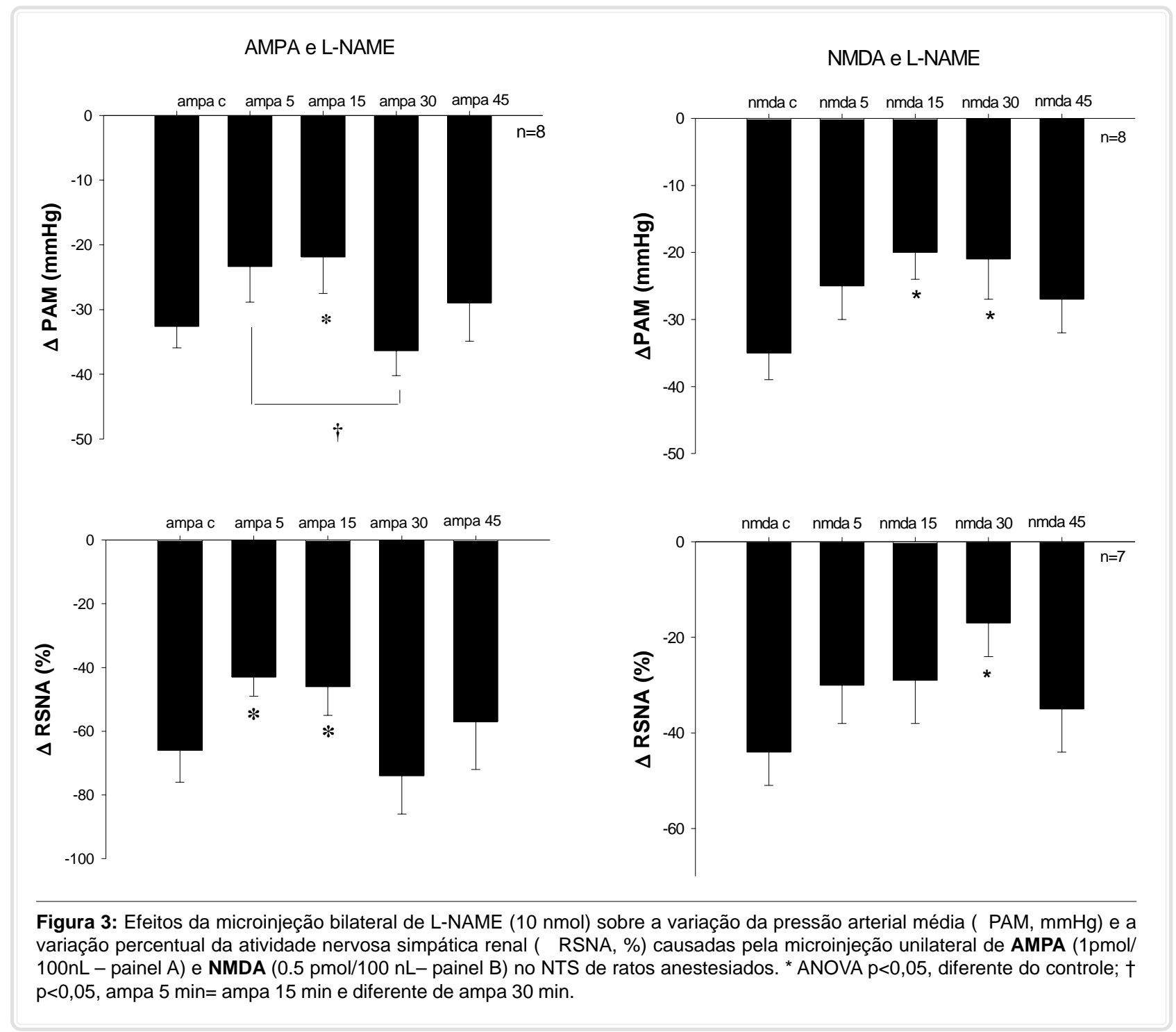

As respostas em estimulação dos reflexos cardiopulmonar e baroceptor também foram alteradas pela inibição da NOS no NTS. O L-NAME reduziu de maneira significante a hipotensão, a bradicardia e a inibição da RSNA causadas pela infusão intra-atrial de fenilbiguanida (PBG) em ratos anestesiados. A inibição da NOS também reduziu a inibição da RSNA causada pelo estímulo do barorreflexo via fenilefrina $^{54}$ (Figura 4).

Em outra etapa, investigamos a função da interação entre a estimulação do receptor não-NMDA (AMPA) e a produção/liberação endógena de NO no NTS de ratos não anestesiados. Como observamos anteriormente $^{41}$, a microinjeção de AMPA no NTS de ratos não anestesiados causa hipertensão, bradicardia e redução inicial do fluxo sanguíneo do leito do trem posterior, seguido por um grande aumento. $\mathrm{O}$ que em associação com as variações da pressão arterial resulta de uma vasoconstrição seguida por vasodilatação no leito do trem posterior (membros inferiores) ${ }^{56}$, resposta similar àquela observada para a microinjeção de L-glu no NTS ${ }^{38}$. A microinjeção do inibidor da NOS (L-NAME) no NTS atenuou significantemente esta vasodilatação ${ }^{56}$.

O que se observa no leito do trem posterior é uma combinação da resposta à estimulação de receptores AMPA (vasoconstrição inicial) e ativação de um sistema vasodilatador dependente de NO. Primeiro, uma rápida e acentuada queda do fluxo sanguíneo que tende a retornar aos valores basais quando a PA aumenta; e segundo, vasodilatação do trem posterior que se torna "visível" quando esta vasoconstrição termina. 


\section{Baroreflex}

A

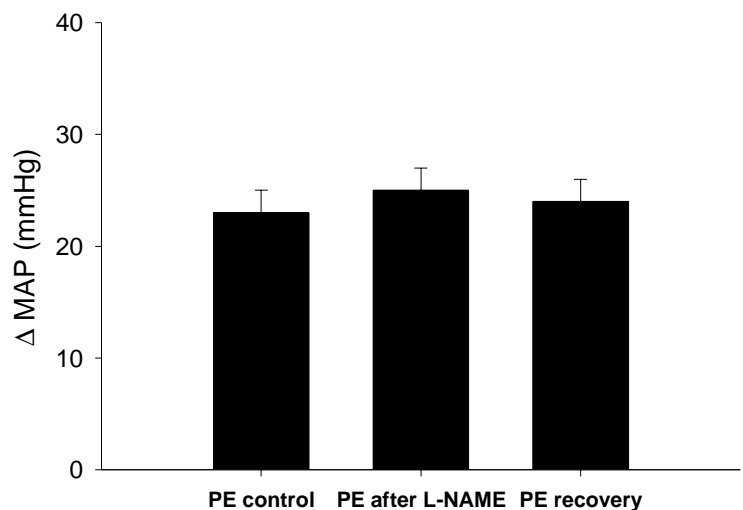

PE control PE after L-NAME PE recovery

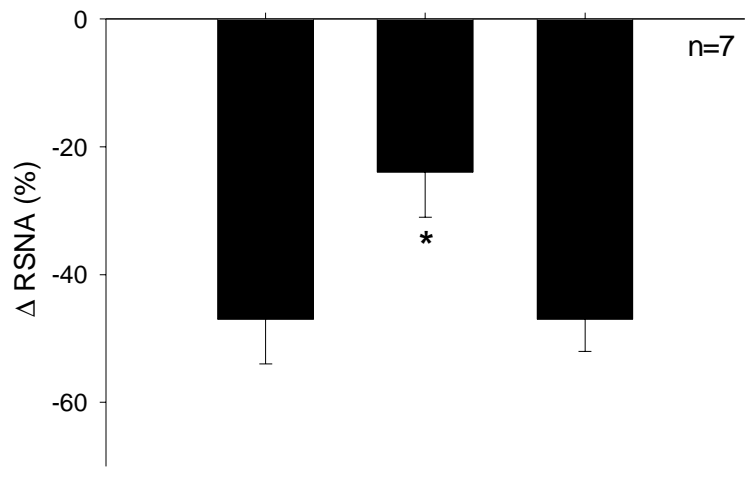

Cardiopulmonary

B
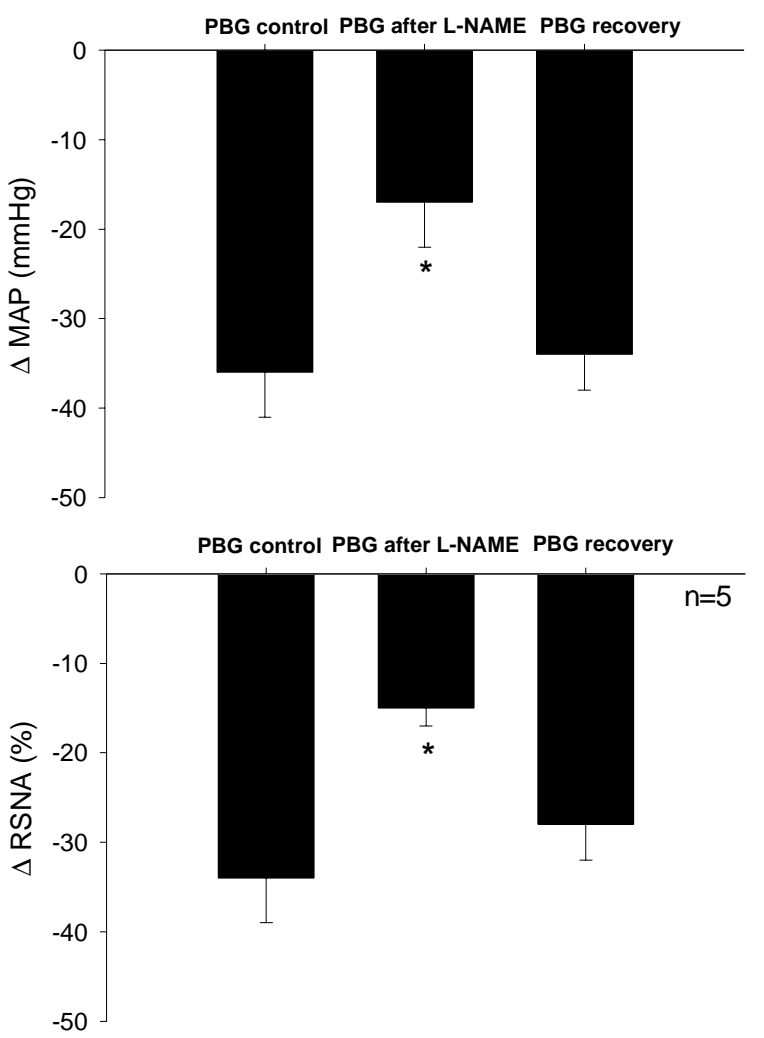

Figura 4: Variação da pressão arterial média ( $\square \mathrm{MAP}, \mathrm{mmHg}$ ) e variação percentual da atividade nervosa simpática renal ( $\square \mathrm{RSNA}$, $\%$ ) causadas pela infusão de fenilefrina (phenylephrine - PE, Baroreflex, painel $A, n=7$ ) e fenilbiguanida (phenylbiguanide - PBG , Cardiopulmonary, painel $B, n=5$ ), antes (control) e depois (after L-NAME) da inibição da NOS pelo L-NAME no NTS de ratos anestesiados. * diferente do controle, $\mathrm{p}<0.05$. Dias et al. $2001^{54}$.

Nós podemos sugerir um sistema vasodilatador dependente de NO (via nitroxidérgica), no NTS, responsável pela modulação do componente simpático (resposta vasoconstritora) quando as aferências glutamatérgicas são ativadas. O estoques pré-formados de NO presentes em neurônios e terminais do NTS e aqueles formados/liberados pela estimulação dos receptores glutamatérgicos, de alguma maneira ainda desconhecida, ativam uma via que resulta em vasodilatação e aumento do fluxo do trem posterior. Quando a via dependente de NO está inibida (inibição da NOS), podemos observar um prolongamento da resposta vasoconstritora causada pela ativação dos receptores AMPA no NTS ${ }^{56}$ (Figura 5).

Os resultados obtidos reforçam a participação do NO no controle cardiovascular via sistema nervoso central (SNC). Esta função parece estar diretamente relacionada com a transmissão glutamatérgica no NTS associada às respostas promovidas pela estimulação dos reflexos cardiovasculares. Os participantes ou componentes (outra áreas do SNC e outros neurotransmissores) desta via mediada pelo NO, no NTS, ainda são desconhecidos e necessitam ser investigados.

\section{4- ÓXIDO NÍTRICO E OUTROS SÍTIOS DE CONTROLE DA PRESSÃO ARTERIAL}

A interação e ação do sistema NO no NTS e nos demais sítios bulbares (CVLM e RVLM) ainda permanecem desconhecidas. Um papel antagônico (facilitatório e inibitório) pode ser sugerido para o NO no NTS uma vez que os estudos realizados até o momento demonstraram respostas controversas no que diz respeito à regulação das variávies cardiovasculares. O papel do NO nos demais sítios bulbares de controle cardiovascular têm sido investigado. No CVLM (medula caudal ventrolateral), a administração de doador de NO (nitroprussiato de sódio) produziu aumento da 


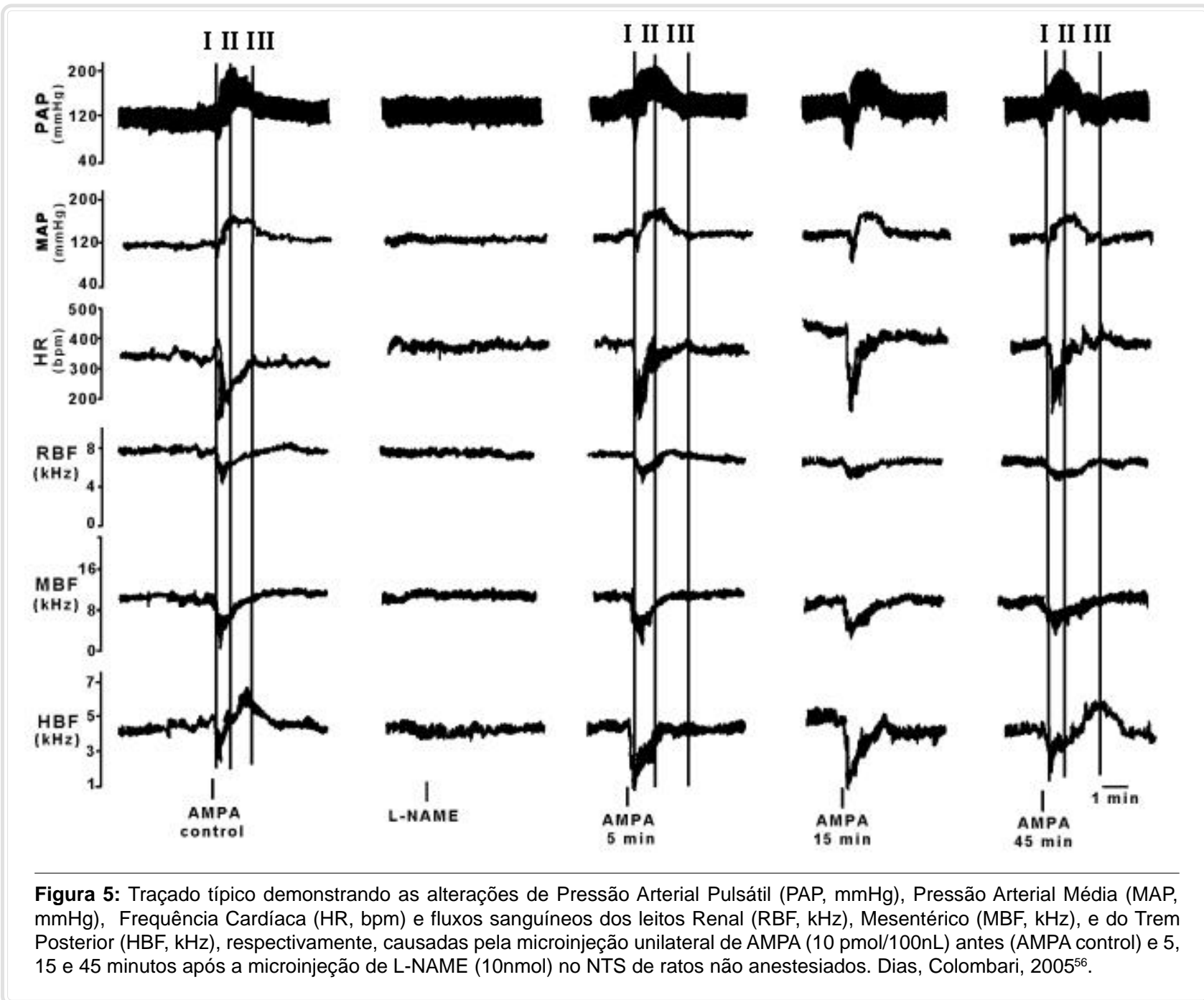

pressão arterial e da atividade nervosa simpática, enquanto a microinjeção do doador de NO causou hipotensão e simpato-inibição ${ }^{57}$. Contudo, os estudos relacionados ao NTS ${ }^{45,48,53,58 / 61}$ e à medula rostroventrolateral (RVLM) $)^{62,63,64}$ mostram funções tanto inibitórias como excitatórias do sistema NO. Estes achados sugerem que a regulação do componente simpático pelo NO possa se dar de maneira diferenciada em diferentes sítios do controle das funções neurovegetativas.

Esta via dependente de NO de origem central, e que é capaz de modular as respostas mediadas pela ativação de receptores glutamatérgicos no NTS não está esclarecida. Em recente estudo de imunohistoquímica foi mostrado que o grupo de neurônios do NTS que projetam para a área pressora do RVLM é similar àquela que contém nNOS imunorreativa, sugerindo que o NO no NTS pode influenciar a transmissão cardiovascular por uma possível via NTS- RVLM ${ }^{65}$.

\section{5- ÓXIDO NÍTRICO E OUTROS NEURO- TRANSMISSORES}

O papel neuromodulatório do NO sobre a liberação de outros neurotransmissores no SNC tem sido também investigada, principalmente em núcleos bulbares e no hipocampo ${ }^{15,66}$.

A liberação de GABA parece ser influenciada pela concentração de NO no hipocampo: níveis basais de NO causam uma redução da liberação de GABA, enquanto o $\mathrm{NO}$ em altas concentrações aumenta sua liberação por dois mecanismos, um $\mathrm{Ca}^{+2}$ - dependente e outros $\mathrm{Na}^{+}$-dependente via carreador ${ }^{67,68}$. Poucas evidências são descritas até o momento no NTS. A única evidência descrita indica que a atividade da nNOS parece influenciar as respostas cardiovasculares causadas pelo GABA no NTS de ratos anestesia$\operatorname{dos}^{69}$. No SNC, o NO facilita a liberação de serotoni- 
na (5-HT) no striatum e hipocampo via aumento de $\mathrm{GMPc}^{70,71}$. A serotonina está associada às funções comportamentais de agressividade e regulação das emoções. O efeito antidepressivo observado com a administração de inibidores da NOS parece ser mediado pela serotonina ${ }^{72}$.

A adenosina age como neuroprotetor endógeno contra danos neuronais e isquemia cerebral. Sua liberação parece ser modulada pelo NO endógeno formada a partir da estimulação dos receptores glutamatérgicos NMDA no hipocampo ${ }^{73}$.

A liberação de histamina do hipotálamo diminui com o aumento da concentração extracelular de $\mathrm{NO}^{74}$. A histamina também é capaz de modificar ou modular a síntese de NO. Receptores $\mathrm{H}_{1}$ podem ativar a NOS através de vias associadas à estimulação da proteína $\mathrm{G}$ resultando em aumento de GMPc interneuronal de neurônios vasopressinérgicos ${ }^{75}$.

Tem sido descrito que o NO modula a liberação de acetilcolina (Ach) em vários sítios do SNC. Acredita-se que o NO endógeno não causa a liberação de Ach diretamente de neurônios colinérgicos, mas sua ação é via estimulação de neurônios glutamatérgicos.

Recentemente, foi demonstrado que o NO eleva os níveis de GMPc em interneurônios colinérgicos no córtex e no striatum ${ }^{76,77}$. Mesmo antes da descoberta da enzima NOS, o marcador histoquímico para NOS, NADPH-diaforase, já havia sido encontrado em neurônios de diversos núcleos colinérgicos ${ }^{77,78,79}$. A colocalização do GMPc e de vesículas de Ach em terminais neuronais de diversas regiões centrais tem sugerido que o NO tem alguma função anterógrada ou retrógrada em determinados neurônios colinérgicos ${ }^{77}$.

A presença de acetilcolinesterase ${ }^{80}$, colina acetiltransferase $^{81}$ e acetilcolina ${ }^{82}$ nos neurônios e terminais do NTS sugerem uma participação desta substância na transmissão do barorreflexo neste núcleo. A remoção do gânglio nodoso ou a vagotomia diminuiram a atividade da acetiltransferase no NTS, sugerindo uma possível aferência colinérgica do gânglio nodoso para o NTS ${ }^{83}$. Esta evidência foi reforçada pela identificação de corpos celulares contendo colina acetiltransferase e a própria acetilcolina (Ach) no gânglio nodoso $0^{84,85}$.

A função da síntese de GMPc mediada por NO em fibras colinérgicas no SNC ainda não é clara. Apesar de poucos estudos fisiológicos relacionando Ach e ativação de NOS-GMPc, especialmente em núcleos bulbares relacionados ao controle cardiovascular (a maioria dos estudos são in vitro e em regiões corti- cais relacionadas a memória e aprendizado).

Em estudos recentes de nosso laboratório investigamos se as respostas cardiovasculares causadas pela Ach microinjetada no NTS de ratos não anestesiados era afetada pela inibição da produção endógena de NO no NTS. A microinjeção no NTS do inibidor não seletivo da NOS (L-NAME), ou do inibidor da nNOS (TRIM) reduziu significantemente a resposta depressora da Ach e reduziu a bradicardia. Este resultado sugere que o NO produzido/liberado centralmente e derivado da NOS neuronal modula a transmissão colinérgica no NTS.

No striatum de camundongos knockout para nNOS ocorreu significante liberação de Ach após a perfusão com doador de $\mathrm{NO}$ (SIN-1); a perfusão com NMDA (agonista glutamatérgico ionotrópico) aumentou a liberação de Ach nos camundongos sham e knockout ${ }^{86}$. Este estudo é uma evidência de que a liberação de Ach no SNC sofre influência da formação/liberação de NO induzida pela ativação de receptores glutamatérgicos.

\section{6- CONCLUSÕES}

A NOS neuronal (nNOS) está presente nos terminais pré- e pós- sinápticos no NTS ${ }^{87}$. Contudo, recentemente foi demonstrado imunohistoquimicamente que a presença da nNOS é predominante nos corpos celulares de neurônios que recebem as aferências vagais, mas a nNOS pré-sináptica não é de origem vagal $^{88}$. Este dado indica que a modulação das respostas cardiovasculares pelo NO pode não só envolver mecanismos intracelulares pelo NO sintetizado no corpo celular do neurônio de segunda ordem que recebe a informação vagal, mas também aquele NO sintetizado e liberado nos terminais adjacentes através de possíveis outros sistemas neurotransmissores que agiriam em diferentes situações fisiológicas associadas à regulação das funções neurovegetativas.

A Figura 6 mostra como o NO de origem central estaria envolvido das alterações hemodinâmicas observadas em nossos estudos: a estimulação das aferências cardiovasculares (ex.: barorreceptores, quimiorreceptores e receptores cardiopulmonares) promove liberação de L-glu nos terminais no NTS. O L-glu ativa os receptores AMPA na membrana pós-sináptica, aumento o influxo de $\mathrm{Ca}^{+2}$ neste neurônio, o que estimula a NOS a produzir NO. Como um composto difusível, o NO pode: 1)estimular a liberação de outros neurotransmissores/neuromoduladores nos termi- 
nais de células adjacentes ou do terminal pré-sináptico (via estimulação da GCs e aumento de GMPc). Dentre estes neurotransmissores podemos citar o GABA, a substância P, a serotonina (5-HT) e a acetilcolina (Ach); 2) ou atuar na ativação/modulação de vias intracelulares de sinalização no próprio neurônio. Esta via poderia envolver a participação (ativação ou inibição) de outras áreas do SNC resultando na vasodilatação do leito do trem posterior em situações de aumento da pressão arterial ${ }^{56}$.

Em suma, os dados aqui apresentados, somados aos da literatura, mostram que o NO produzido e liberado centralmente pode influenciar a transmissão glutamatérgica no NTS modulando as respostas cardiovasculares. A função específica, ou o mecanismo de ação desta interação L-glu-NO ainda não está esclarecido e pode envolver o controle da liberação de outros neurotransmissores pelo $\mathrm{NO}$, bem como a participação de outros sítios bulbares de controle neural da pressão arterial.

\section{7- PERSPECTIVAS}

Durante a hipertensão crônica ocorrem alterações fisiológicas e farmacológicas dos neurônios do NTS: o limiar de pressão necessário para ativar os baroceptores está aumentado ${ }^{89 / 94}$, e a sensibilidade dos receptores para aumentos da pressão arterial está diminuída ${ }^{89,90,94,95}$. Comparando com animais normotensos, os animais hipertensos apresentam um aumento significante das aferências excitatórias para o NTS. Estudos demonstraram que a resposta pressora resultante da microinjeção de baclofen (agonista GABAb) no NTS de ratos está alterada durante a hipertensão aguda e crônica sugerindo uma adaptação das vias aferentes periféricas durante a hipertensão aguda ou em curto prazo e, em nível neuronal em longo prazo (hipertensão crônica) ${ }^{96}$. Zhang e Mifflin (2000) ${ }^{97}$ observaram que a frequência de disparos da maioria dos neurônios do NTS não está alterada durante a hipertensão crônica.

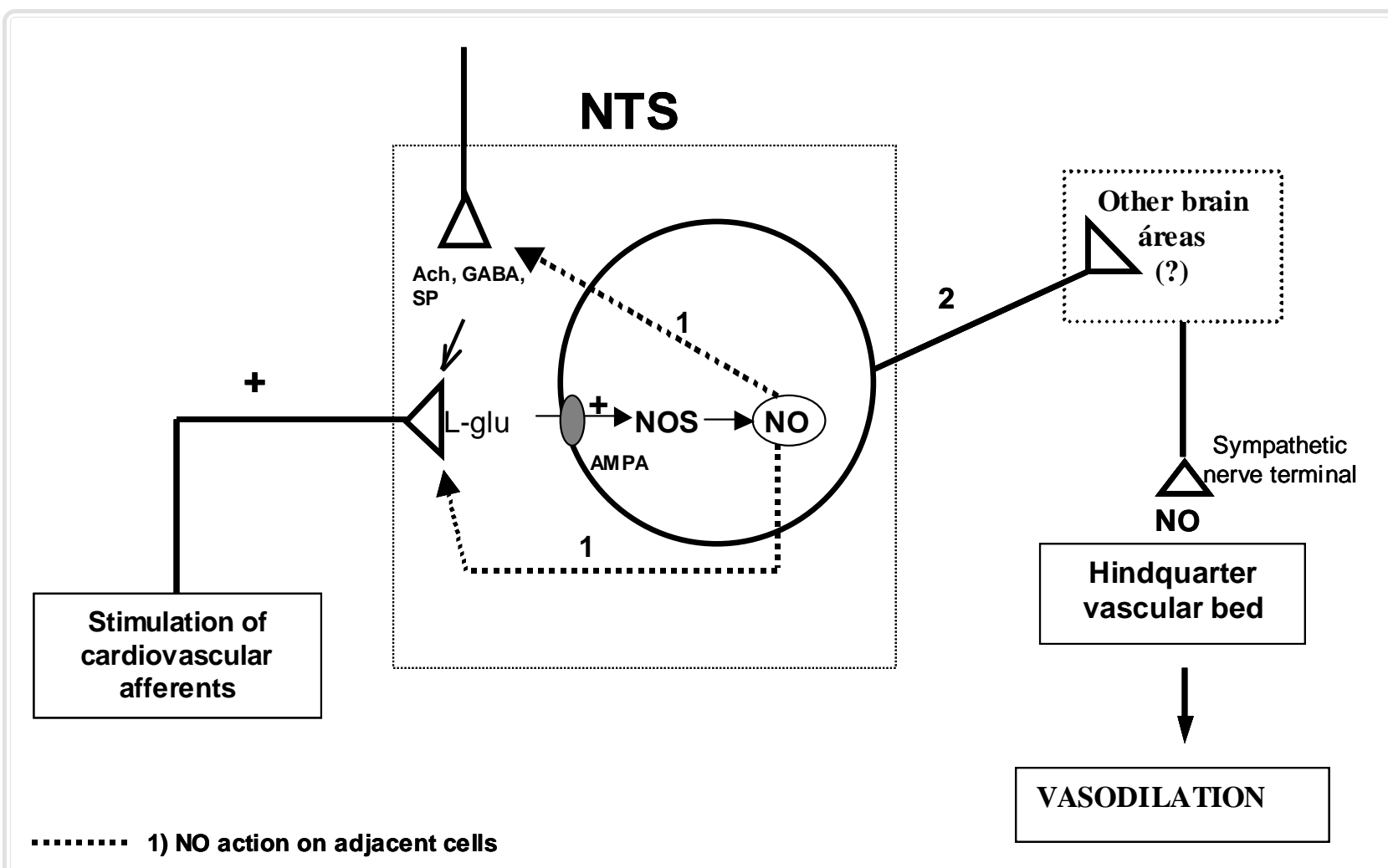

2) Activation of the vasodilatatory nitroxidergic pathway

Figura 6: Representação esquemática mostrando os possíveis mecanismos de ação do NO de origem neuronal na modulação da transmissão glutamatérgica no NTS frente à estimulação das aferências cardiovasculares. Dias, Colombari, $2005^{56}$. 
Evidências recentes sugerem uma "plasticidade homeostática" das vias neuronais a fim de estabilizar a atividade da rede nervosa durante alterações em longo prazo na excitabilidade destas vias. Esta plasticidade envolve mecanismos capazes de regular a excitabilidade neuronal e estabilizar a transmissão sináptica total, uma maneira de normalizar os disparos neuronais no NTS e manter algum grau da capacidade de ajuste da pressão arterial ${ }^{98}$.

Nossos estudos mostram a participação do NO na modulação da transmissão glutamatérgica e dos reflexos cardiovasculares no NTS. O estudo das alterações farmacológicas e fisiológicas do sistema L-glu/NO que ocorrem durante a hipertensão são de grande importância para um melhor entendimento da regulação cardiovascular. Isto contribuiria para esclarecer os mecanismos envolvidos na manutenção das funções neurovegetativas, minimizando inesperadas mudanças na função cardiovascular de indivíduos comprometidos (hipertensos), e teria potencial aplicação terapêutica em circunstâncias onde a função reflexa não está mantida.

\section{AGRADECIMENTOS}

Os estudos citados nesta revisão foram desenvolvidos e estão em desenvolvimento com o apoio financeiro da FAPESP, CNPq e CNPq/PRONEX.

Dias ACR, Silva LG, Colombari E. Nitric oxide (NO) in the neural control of blood pressure: modulation of glutamatergic transmission within the NTS. Medicina (Ribeirão Preto) 2006; 39 (1): 51-64.

ABSTRACT: The neuromodulatory effect of nitric oxide (NO) on glutamatergic transmission within the NTS related to cardiovascular regulation has been widely investigated. Activation of glutamatergic receptors in the NTS stimulates the production and release of NO and other nitrosyl substances with neurotransmitter/neuromodulator properties. The presence of NOS, including the protein nNOS and its mRNA in vagal afferent terminals in the NTS and nodose ganglion cells suggest that NO can act on glutamatergic transmission. We previously reported that iontophoresis of L-NAME on NTS neurons receiving vagal afferent inputs significantly decreased the number of action potentials evoked by iontophoretic application of AMPA. In addition, iontophoresis of the NO donor papaNONOate enhanced spontaneous discharge and the number of action potentials elicited by AMPA, suggesting that NO could be facilitating AMPA-mediated neuronal transmission within the NTS. Furthermore, the changes in renal sympathetic discharge during activation of baroreceptors and cardiopulmonary receptors involve activation of AMPA and NMDA receptors in the NTS and these responses are attenuated by microinjection of L-NAME in the NTS of conscious and anesthetized rats. Cardiovascular responses elicited by application of NO in the NTS are closely similar to those obtained after activation of vagal afferent inputs, and L-glutamate is the main neurotransmitter of vagal afferent fibers. In this review we discuss the possible neuromodulatory mechanisms of central produced/released NO on glutamatergic transmission within the NTS.

keywords: $\quad$ AMPA. NMDA. Nitric Oxide. Regional Blood Flow. Blood Pressure. NTS.

\section{REFERÊNCIAS}

1 - Lin L-H, Talman WT. Soluble guanylate cyclase and neuronal nitric oxide synthase colocalize in rat nucleus tractus solitarii. J Chem Neuroanat 2005; 29: 127-36.

2 - Talman WT, Dragon DN, Ohta H, Lin L-H. Nitroxidergic influences on cardiovascular control by NTS: A link with glutamate. Ann N Y Acad Sci 2001; 940: 169-78.

3 - Lawrence AJ, Jarrott B. Neurochemical modulation of cardiovascular control in the nucleus tractus solitarius. Prog Neurobiol 1996; $48: 21-53$.
4 - Feldman JL, Ellenberger HH. Central coordination of respiratory and cardiovascular control in mammals. Annu Rev Physiol 1988; 50: 593-606.

5 - Ruggiero DA, Pickel VM, Milner TA, Anwar M, Otake K, Mtui EP, Park D. Viscerosensory processing in the nucleus tractus solitarii; structural and neurochemical subtrates. In: Barraco IRA, ed. Nucleos of solitary tract. Boca Raton: CRC Press; 1994. p. 3-34.

6 - Talman WT, Perrone MH, Reis DJ. Evidence for L-glutamate as the neurotransmitter of baroreceptor afferent nerve fibers. Science 1980; 209: 813-5. 
7 - Criscione L, Reis DJ, Talman WT. Cholinergic mechanisms in the nucleus tractus solitarii and cardiovascular regulation in the rat. Eur J Pharmacol 1983; 88: 47-55.

8 - Landulpho CDAP, Dias ACR, Colombari E. Cardiovascular mechanisms activated by microinjection of baclofen into the NTS of conscious rats. Am J Physiol Heart Circ Physiol 2003; 284: 987-93.

9 - Abdala AP, Haibara AP, Colombari E. Cardiovascular responses to substance $P$ in the nucleus tractus solitarii: microinjection study in conscious rats. Am J Physiol Heart Circ Physiol 2003; 285: H891-8.

10 - Bauman MN, Wang D, Luschei ES, Talman WT. Effect of substance $P$ injection into the nucleus tractus solitarius of rats on cricothyroid and thyroarytenoid motor activity and cardiovascular and respiratory systems. Ann Otol Rhinol Laryngol 2002; 111: 875-83.

11 - Esplugues JV. NO as a signalling molecule in the nervous system. Br J Pharmachol 2002; 135: 1079-95.

12 - Garthwaite J, Boulton CL Nitric oxide signaling in the central nervous system. Annu Rev Physiol 1995; 57: 683-706.

13 - Bredt DS, Snyder SH. Nitric oxide mediates glutamatelinked enhancement of cGMP levels in the cerebellum. Proc Natl Acad Sci USA 1989; 86: 9030-3.

14 - Garthwaite J, Garthwaite G, Palmer RM, Moncada S. NMDA receptor activation induces nitric oxide synthesis from arginine in rat brain slices. Eur J Pharmacol 1989; 172: 413-6.

15 - Patel Kp, Li Y-F, Hirooka Y. Role of nitric oxide in central sympathetic outflow. Exp Biol Med 2001; 226: 814-24.

16 - Bates TE, Loesh A, Burnstock G, Clark JB. Immunocytochemical evidence for a mitochondially located nitric oxide synthase in brain and liver. Biochem Biophys Res Commun 1995; 213: 896-900.

17 - Brown GC, Cooper CE Nanomolar concentrations of nitric oxide reversibly inhibit synaptosomal respiration competing with oxygen at cytocrome oxidase. FEBS Lett 1994; 356: 295-8

18 - Dinerman JL, Dawson TM, Schell MJ, Snowman A, Snyder $\mathrm{SH}$. Endothelial nitric oxide synthase localized to hippocampal pyramidal cell: implications for synaptic plasticity. Proc Natl Acad Sci USA 1994; 91: 4214-8.

19 - Wiencken AE, Casagrande VA. Endotelial nitric oxide synthetase (eNOS) in astrocytes: another source of nitric oxide in neocortex. Glia 1999; 26: 280-90.

20 - Murphy S. Production of nitric oxide by glial cell: regulation and potential roles in the CNS. Glia 2000; 29: 1-14.

21 - Nagase S, Takemura K, Ueda A, Hirayama A, Aoyagi K, Kondoh M, Koyama A. A novel nonenzymatic pathway for the generation of nitric oxide by the reaction of hydrogen peroxide and D- or L-arginine. Biochem Biophys Res Commun $1997 ; 233: 150-3$

22 - Maiese K, Boccone L. Neuroprotection by peptide growth factors against anoxia and nitric oxide toxicity requires modulation of protein kinase C. J Cereb Blood Flow Metab 1995; 15: $440-9$.

23 - Ignarro LJ. Signal transduction mechanisms involving nitric oxide. Biochem Pharmacol 1991; 41: 485-90.
24 - Schmidt HH, Gagne GD, Nakane M, Pollock JS, Miller MF, Murad F. Mapping of neural nitric oxide synthase in the rat suggests frequent co-localization with NADPH diaphorase but not with soluble guanylyl cyclase, and novel paraneural functions for nitrinergic signal transduction. J Histochem Cytochem 1992; 40: 1439-56.

25 - Southam F, Garthwait J. The nitric oxide cyclic GMP signalling pathway in the rat brain. Neuropharmacology 1993; 32 : 1267-77.

26 - Young HM, Mccolague K, Furness JB, De Ventre J. Nitric oxide targets in the guinea-pig intestine identified by induction of cyclic GMP immunoreactivity. Neuroscience 1993; 55: 583-96.

27 - Seregelyes C, Igamberdiev AU, Maassen A, Hennig J, Dudits $D$, Hill RD. NO-degeneration by alfalfa class 1 hemoglobin (Mhb1): a possible link to PR-1a gene expression in Mhb1overproducing tobacco plants. FEBS Lett 2004; 571: 61-6.

28 - Muller B, Kleschyov AL, Alencar JL, Vanin A, Stoclet JC. Nitric oxide transport and storage in the cardiovascular system. Ann NY Acad Sci 2002; 992: 131-9.

29 - Moncada S, Higgs A, Furchgott R. International Union of Pharmacology nomenclature in nitric oxide research. Pharmacol Rev 1997; 49: 137-42.

30 - Bredt DS, Hwang PM, Snyder SH. Localization of nitric oxide synthase indicating a neural role for nitric oxide. Nature 1990; 347: 768-70.

31 - Huang PL. Neuronal and endothelial nitric oxide synthase gene knockout mice. Braz J Med Biol Res 1999; 32: 1353-9.

32 - Estrada C, Defelipe J. Nitric oxide-producing neurons in the neocortex: Morphological and functional relationship with intraparenchimal microvasculature. Cereb Cortex 1998; 8: 193-203.

33 - Di Paola ED, Vidal MJ, Nistico G. L-Glutamate evokes the release of an endothelium-derived relaxing factor-like substance from the rat nucleus tractus solitarius $\mathrm{J}$ Cardiovasc Pharmacol 1991; 17 (Suppl 3): 269-72.

34 - Garthwaite J. Glutamate, nitric oxide and cell-cell signalling in the nervous system. Trends Neurosci 1991; 14: 60-7.

35 - Kristensson K, Aldskogius M, Peng ZC, Olsson T, Aldskogius $\mathrm{H}$, Betivoglio $\mathrm{M}$. Co-induction of neuronal interferum-gamma and nitric oxide synthase in rat motor neurons after axotomy: a role in nerve repair or death? J Neurocytol 1994; 23: 453-9.

36 - Lü Y, Ding YQ, Quin BZ, Li JS. The distribution and origim of axon terminals with NADPH doaphorase activity in the nucleus of solitary tract of the rat. Neurosci Lett 1994; 171: 70-2.

37 - Ruggiero DA, Mtui EP, Otake K, Anwar M. Central and primary visceral afferents to nucleus tractus solitarii may generate nitric oxide as a membrane-permeant neuronal messenger. J Comp Neurol 1996; 364: 51-67.

38 - Colombari E, Davisson RL, Shaffer RA, Talman WT, Lewis SJ. Hemodynamic effects of L-glutamate in NTS of conscious rats: a possible role of vascular nitrosyl factors. Am J Physiol 1998; 274: 1066-74.

39 - Davisson RL, Shaffer RA, Johnson AK, Lewis SJ. Stimulation of lumbar sympathetic nerves may produce hindlimb vasodilation via the release of pre-formed stores of nitrosyl factors. Neuroscience 1996; 72: 881-7. 
40 - Davisson RL, Shaffer RA, Johnson AK, Lewis SJ. Usedependent loss of active sympathetic neurogenic vasodilation after nitric oxide synthase inhibition in conscious rats. Evidence for the presence of preformed stores of nitric oxide-containing factors. Hypertension 1996; 28: 347-53.

41 - Dias ACR, Talman WT, Colombari E. Hemodynamic effects elicited by microinjection of glutamatergic agonists into the NTS of conscious rats. Am J Physiol 2001; 281: 1026-34.

42 - Zhang J, Mifflin SW. Differential roles for NMDA and nonNMDA receptor subtypes in baroreceptor afferent integration in the nucleus of the solitary tract of the rat. $\mathrm{J}$ Phisiol 1998; 511: 733-45.

43 - Botsford SA, Dean C, Hopp FA, Seagard JL. Presence of glutamate receptor subtypes on barosensitive neurons in the nucleus tractus solitarius of the dog. Neurosci Lett 1999; 261: 113-7.

44 - Seagard JL, Dean C, Hopp FA. Neurochemical transmission of baroreceptor input in the nucleus tractus solitarius. Brain Res Bull 2000; 51: 111-8.

45 - Lin H-C, Wan F-J, Tseng C-J. Modulation of cardiovascular effects produced by nitric oxide and ionotropic glutamate receptor interaction in the nucleus tractus solitarii of rats. Neuropharmacology 1999; 38: 935-41.

46 - Lin L-H, Emson PC, Talman WT. Apposition of neuronal elements containing nitric oxide synthase and glutamate in the nucleus tractus solitarii of rat: A confocal microscopy analysis. Neuroscience 2000; 96: 341-50.

47 - Esteves FOG, Mcwilliam PN, Batten TFC. Nitric oxide producing neurones in the rat medulla oblongata that projects to nucleus solitarii. J Chem Neuroanat 2000; 20: 185-97.

48 - Harada S, Tokunaga S, Momohara M, Masaki H, Tagawa T, Imaizumi T, Takeshita A. Inhibition of nitric oxide formation in the nucleus tractus solitarius increases renal sympathetic nerve activity in rabbits. Circ Res 1993; 72: 511-6.

49 - Togashi H, Sakuma I, Yoshioka M, Kobayashi T, Yasuda H, Kitabatake A, Saito H, Gross SS, Levi R. A central nervous system action of nitric oxide in blood pressure regulation. J Pharmacol Exp Ther 1992; 262: 343-7.

50 - Lewis SJ, Machado BH, Ohta H, Bates JN, Talman, WT Microinjection of S-nitrosocysteine into the nucleus tractus solitarii decreases arterial pressure and heart rate via activation of soluble guanylate cyclase. Eur J Pharmacol 1991; 202: 135-6.

51 - Machado BH, Bonagamba LGH. Microinjection of S-nitrocysteine into the nucleus tractus solitarii of conscious rats decreases arterial pressure but L-glutamate does not. Eur J Pharmacol 1992; 221: 179-82.

52 - Sakai K, Hirooka Y, Matsuo I, Eshima K, Shigematsu H, Shimokawa H, Takeshita A. Overexpression of endothelial nitric oxide synthase in the nucleus tractus solitarii causes hypotension and bradycardia in vivo. Hypertension 2000; 36: 1023-8.

53 - Dias ACR, Colombari E, Mifflin SW. Effect of nitric oxide on excitatory amino acid evoked discharge of neurons in the nucleus of the solitary tract. Am J Physiol Heart Circ Physiol 2003; 284: 234-40.
54 - Dias ACR, Vitela M, Colombari E, Mifflin SW. Nitric oxide modulation of glutamatergic, baroreflex, and cardiopulmonary transmission in the nucleus of the solitary tract. Am J Physiol Heart Circ Physiol 2005; 288: 256-62.

55 - Lo W, Lin H, Ger L, Tung C, Tseng C. Cardiovascular effects of nitric oxide and $\mathrm{N}$-methil-D-aspartate receptors in the nucleus tractus solitarii of rats. Hypertension 1997; 30: 1499-503.

56 - Dias ACR, Colombari E. Central nitric oxide modulates hindquarter vasodilation elicited by AMPA receptors stimulation into the NTS of conscious rats. Am J Physiol Regul Integr Comp Physiol 2006; 290: R1330-6.

57 - Shapoval LN, Sagach VF, Pobegailo LS. Nitric oxide influences ventrolateral medullary mechanisms of vasomotor control in the cat. Neurosci Lett 1991; 86: 9030-3.

58 - Manzoni O, Prezeau L, Marin P, Deshager S, Bockaert J, Fagni L. Nitric oxide-induced blockade of NMDA receptors. Neuron 1992; 8: 653-62.

59 - Tagawa T, Imaizumi T, Harada S, Endo T, Shiramoto M, Hirooka Y, Takeshita A. Nitric oxide influences neuronal activity in the nucleus tractus solitarius of rat brainstem slices. Circ Res 1994; 75: 70-6.

60 - Zanzinger J, Czachurski J, Seller H. Neuronal nitric oxide reduces sympathetic excitability by modulation of central glutamate effects in pigs. Circ Res 1997; 80: 565-71.

61 - Matsuo I, Hirooka Y, Hironaga K, Eshima K, Shigematsu H, Shihara M, Sakai K, Takeshita A. Glutamate release via NO production evoked by NMDA in the NTS enhances hypotension and bradycardia in vivo. Am J Physiol Integr Comp Physiol 2001; 280: 1285-91.

62 - Zanzinger J, Czachurski J, Seller H. Effects of nitric oxide on sympathetic baroreflex transmission in the nucleus tractus solitarii and caudal ventrolateral medulla in cats. Neurosci Lett 1995; 197: 199-202.

63 - Hirooka Y, Polson JW, Dampney RAL. Pressor and sympathoexcitatory effects of nitric oxide in the rostral ventrolateral medulla. J Hypertens 1996; 14: 1317-24.

64 - Martins-Pinge MC, Baraldi-Passy I, Lopes OU. Excitatory effects of nitric oxide within the rostral ventrolateral medulla of freely moving rats. Hypertension 1997; 30: 704-7.

65 - Kantzides A, Badoer E. nNOS-containing neurons in the hypothalamus and medulla project to RVLM. Brain Res 2005; 1037: $25-34$

66 - Guix FX, Uribesalgo I, Coma M, Muñoz FJ. The physiolgy and pathophysiology of nitric oxide in the brain. Prog Neurobiol 2005; 76: 126-52.

67 - Getting SJ, Segieth J, Ahamad S, Biggs CS, Whitton PS. Bophasic modulation of GABA release by nitric oxide in the hippocampus of freely moving rats in vivo. Brain Res 1996; 717: 196-9.

68 - Ohkuma S, Katsura M, Chen DZ, Narihara H, Kuriyama K Nitric oxide-evoked $[3 \mathrm{H}]$ gamma-aminobutyric acid release is mediated by two distinct release mechanims. Brain Res Mol Brain Res 1996; 36: 137-44.

69 - Shapoval LM, Sahach VF, Pobihailo LS, Stepanenko LH, lermolins'ka NV. Role of nitric oxide in effects of intramedullary injected gamma-aminobutyric acid on blood circulation. Fiziol Zh 2005; 51: 43-50. 
70 - Kaehler ST, Singewald N Sinner C, Philippu A. Nitric oxide modulates the release of serotonin in the rat hypothalamus. Brain Res 1999; 835: 346-9.

71 - Trabace L, Cassano T, Tucci P, Steardo L, Kendrick KM, Cuomo V. The effects of nitric oxide on striatal serotoninergc transmission involve multiple targets: an in vivo microdialysis study in the awake rat. Brain Res 2004; 1008: 293-8.

72 - Harkin A, Connor TJ, Walsh M, St. John N, Kelly JP. Serotonergic mediation of the antidepressant-like effects of nitric oxide synthase inhinbitors. Neuropharmacology 2003; 44: 616-3.

73 - Saransaari P, Oja SS. Involviment of nitric oxide in adenosine release in the developing and adult mouse hippocampus. Neurochem Res 2004; 29:219-25.

74 - Prast H, Lamberti C, Fischer H, Tran MH, Philippu A. Nitric oxide influences the release of histamine and glutamate in the rat hypothalamus. Naunyn Schmiedebergs Arch Pharmacol 1996; 354: 731-5.

75 - Yang Qz, Hatton GI. Histamine H1-receptor modulation of interneuronal coupling among vasopressinergic neurons depends on nitric oxide synthase activation. Brain Res 2002; 955: 115-22.

76 - De Vente J, Ittersum MM, Axer H, Steinbusch HWM. Nitricoxide-induced cGMP synthesis in cholinergic neurons in the rat brain. Exp Brain Res 2001; 136: 480-91.

77 - De Vente J. cGMP: a second messenger for acetylcoline in the brain? Neurochem Int 2004; 45: 799-812.

78 - Vicent SR, Satoh K, Armstrong DM, Fibiger HC. NADPH-diaphorese: aselective histochemical marker for the cholinergic neurons of the pontine reticular formation. Neurosci Lett 1983; 43: 31-6.

79 - Ellison DW, Kowall NW , MARTIN JB. Subset of neurons characterized by the presence of NADPH-diaphorese in human substantia innominata. J Comp Neurol 1987; 260: 233-45.

80 - Palkovits M, Jacobowitz DM. Topographic atlas of catecholamine and acetylcholinesterase-containing neurons in the rat brain. II. Hindbrain (mesencephalon, rhombencephalom). J Comp Neurol 1974; 157: 29 - 42.

81 - Kobayashi RM, Brownstein M, Saavedra JM, Palkovits M. Choline acetyltransferase content in discrete regions of the rat brain stem. J Neurochem 1975; 24: 637-40.

82 - Helke CJ, Muth EA, Jacobowitz DM. Changes in central cholinergic neurons in the spontaneously hypertensive rat. Brain Res 1980; 188: 425-36.

83 - Helke CJ, Handelmann GE, Jacobowitz DM. Choline acetyltransferase activity in the nucleus tractus solitarius: regulation by afferent vagus nerve. Brain Res Bull 1983; 10: $433-6$.

84 - Palouzier B, Chamoin-Barrit MC, Portalier P, Ternaux JP. Cholinergic neurons in the rat nodose ganglia. Neurosci Letters 1987; 80: 147-52.
85 - Ternaux JP, Falempin M, Palouzier B, Chamoin MC, Portalier P. Presence of cholinergic neurons in the vagal system: biochemical and imunohistochemical approaches. J Auton Nerv Syst 1989; 28: 233 - 42.

86 - Buchholzer ML, Klein J. NMDA-induced acetylcholine release in mouse stiratum: role of NOS synythase isoforms. $J$ Neurochem 2002; 82: 1558-60.

87 - Lin L-H, Cassel MD, Sandra A, Talman WT. Direct evidence for nitric oxide synthase in vagal afferents to the nucleus tractus solitarii. Neuroscience 1998; 84: 549-58.

88 - Atkinson L, Batten TFC, Corbett EKA, Sinfield JK, Deuchars J. Subcellular localization of neuronal nitric oxide synthase in the rat nucleus of the solitary tract in relation to vagal afferent inputs. Neuroscience 2003; 118: 115-22.

89 - Chapleau MW, Hajduczok G, Abboud FM. Mechanism of decreased baroreceptor activity in chronic hypertensive rabbits. Role of endogenous prostanoids. J Clin Invest 1990; 86:625-30.

90 - Jones JV. Time course and extent of carotid sinus baroreceptor threshold resetting in rats with renovascular hypertension, Acta Physiol Scand 1977; 99:173-82.

91 - Krieger EM, Salgado HC, Michelini LC. Resetting of the baroreceptors, In: Guyton AC, Hall JE, eds. Cardiovascular physiology IV. Baltimore: University Park Press; 1982. p. 119-45.

92 - Moreira ED, Ida F, Krieger EM. Reversibility of baroreceptor hyposensitivity during reversal of hypertension. Hypertension $1990 ; 15: 791-6$

93 - Moreira ED, Ida F, Oliveira VLL, Krieger EM. Early depression of the baroreceptor sensitivity during onset of hypertension. Hypertension 1992; 19(II): II-198 - II-201.

94 - Qadri F, Arens T, Schwartz E-C, Häuser W, Dendorfer A, Dominiak P. Brain nitric oxide synthase activity in spontaneously hypertensive rats during the development of hypertension. J Hypertens 2003; 21: 1687-94.

95 - Thoren PN, Andresen MC, Brown AM. Resetting of aortic baroreceptors with nonmyelinated afferent fibers in spontaneously hypertensive rats. Acta Physiol Scand 1983; 117: $91-7$.

96 - Vitela M, Mifflin SW. $\gamma$-Aminobutyric Acid $_{B}$ receptor-mediated responses in the Nucleus Tractus Solitarius are altered in acute and chronic hypertension. Hypertension 2001; 37(part 2): 619-22.

97 - Zhang J, Mifflin SW. Integration of aortic nerve inputs in hypertensive rats. Hypertension 2000; 35 (part 2): 430-6.

98 - Turrigiano GG. Homeostatic plasticity in neuronal networks: the more things change, the more they stay the same. Trends Neurosci 1999; 22: 221-7. 